\section{JURNAL PHROPHINTI Junnal Kälian Sosioloni dan Pendidikan}

Jurnal Perspektif: Jurnal Kajian Sosiologi dan Pendidikan Vol. 3 No. 1 Tahun 2020

http://perspektif.ppj.unp.ac.id

Email: perspektif@ppi.unp.ac.id

ISSN: 2622-1748 (Online), 2684-902X (Print)

DOI: http://dx.doi.org/10.24036/perspektif.v3i1.212

\title{
Strategi Pengamen dalam Meningkatkan Ekonomi di Kawasan Wisata Pantai Puruih Kota Padang
}

\author{
Dian Nofrianti ${ }^{1}$, Nora Susilawati ${ }^{2}$ \\ ${ }^{1.2}$ Universitas Negeri Padang
}

Email: dianjulian38@gmail.com, susilawatinora@gmail.com

\begin{abstract}
Abstrak
Penelitian ini dilatarbelakangi oleh penggunaan lokasi wisata Pantai Puruih, selain dimanfaatkan untuk tempat wisata juga dimanfaatnkan sebagai tempat untuk mencari nafkah. Salah satu pencari nafkah yang ditemukan yaitu pengamen. Pengamen memanfaatkan kawasan wisata Pantai Puruih yang banyak dikunjungi ini untuk mencari nafkah demi memenuhi kebutuhan keluarga. Tujuan penelitian ini adalah mendeskripsikan strategi pengamen dalam meningkatkan ekonomi di Kawasan Wisata Pantai Puruih Padang. Penelitian ini dianalisis dengan menggunakan teori tindakan sosial yang dikemukakan oleh Max Weber, yang menjelaskan tindakan yang berorientasi pada motif dan tujuan pelaku. Menurut Weber terdapat empat tipe tindakan sosial, pertama yaitu tindakan rasional instrumental, kedua yaitu tindakan rasional nilai, ketiga yaitu tindakan afektif, keempat yaitu tindakan tradisional. Pendekatan penelitian ini menggunakan pendekatan penelitian kualitatif dengan tipe penelitian studi kasus, teknik pemilihan informan purposive sampling dengan jumlah informan 13 orang. Pengumpulan data dilakukan dengan cara wawancara dan observasi yang dianalisis dengan meggunakan teknik analisis data oleh Miles dan Huberman. Strategi pengamen dalam meningkatkan ekonomi yaitu dengan mengoptimalkan pendidikan anak. Pengamen memilih memenuhi kebutuhan sekolah anak-anaknya daripada membeli hal-hal lain dan menyisihkan sebagian hasil mengamen agar dapat menjadi modal untuk meningkatkan sumber mata pencahariannya.
\end{abstract}

Kata kunci: Meningkatkan Ekonomi, Pengamen, Strategi

\section{Abstract}

This research is motivated by the use of Puruih Beach tourist sites, in addition to being used for tourist attractions, it is also used as a place to make a living. One of the breadwinners found was busker. Buskers take advantage of the much-visited Puruih Beach tourist area to make a living to meet family needs. The purpose of this study is to describe the busking strategy in improving the economy in the Padang Puruih Beach Tourism Area. This study was analyzed using the theory of social action put forward by Max Weber, who explained the actions which were oriented towards the motives and goals of the actors. According to Weber there are four types of social action, first is rational instrumental action, second is value rational action, third is affective action, fourth is traditional action. This research approach uses a qualitative research approach with the type of case study research, the technique of selecting purposive sampling with 13 informants. Data collection was carried out by means of interviews and observations which were analyzed using data analysis techniques by Miles and Huberman. Busking strategy in improving the economy is to optimize children's education. Buskers choose to meet the children's school needs rather than buy other things and set aside some of the busking results so that it can be capital to increase their livelihoods.

Keywords: Buskers, Improve the economy, Strategies

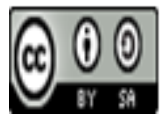

Received: January 16, 2019 


\section{Pendahuluan}

Pariwisata merupakan sebuah industri yang perkembangannya kian pesat setiap tahunnya (Husni, A, 2019). Pariwisata merupakan suatu hal yang penting bagi suatu negara terutama pemerintah daerah tempat objek wisata itu berada (Antoro, 2014). Selain itu, pembangunan dan perkembangan suatu daerah menjadi kawasan wisata tidak lepas dari partisipasi aktif masyarakat lokal (Syafrini, D, Susilawati, N, 2016).

Sektor pariwisata merupakan salah satu sektor pembangunan dibidang ekonomi. Perkembangan pariwisata berdampak terhadap kondisi sosial ekonomi masyarakat. Salah satunya bagi masyarakat yang bijak dalam memanfaatkan lokasi wisata yang ramai dikunjungi hingga menjadi sumber pendapatan bagi masyarakat. Sebagai sumber penerimaan pendapatan, pariwisata tidak terlepas dari pengaruh jumlah kunjungan wisatawan (Purwanti, 2013). Pembangunan pariwisata dimaksudkan untuk menyuguhkan suatu obyek yang dapat memuaskan para wisatawan, sehingga dapat memberikan suatu dampak yang positif terhadap pemasaran produk pariwisata dimasa yang akan datang (Prihandoko, 2008). Selain itu perbaikan fasilitas di lokasi wisata juga mempengaruhi jumlah wisatawan yang datang ke tempat wisata karena semakin baik dan nyaman fasilitas yang tersedia pada lokasi wisata maka akan mendorong wisatawan ke tempat lokasi karena nyaman, begitu pula sebaliknya (Rohman, 2016). Dapat dikatakan pergeseran kebijakan kota menjadi kota wisata akan mengubah wajah kota dan membangkitakn kembali perekonomian kota (Syafrini Delmira, 2017).

Daerah Sumatera Barat memiliki potensi pariwisata dari sisi alam, budaya dan sejarah. Keindahan alam destinasi wisata Sumatera Barat sudah banyak dikenal di Indonesia bahkan di luar negeri. Sedangkan budaya orang Minangkabau juga beberapa sudah menjadi icon pariwisata Sumatera Barat. Selain itu budaya kuliner orang Minangkabau dan songket juga sangat terkenal bagi wisatawan (Fitriani, 2018). Angka kunjungan wisatawan ke Sumatera Barat terus mengalami peningkatan. Berdasarkan data dari Dinas Kebudayaan dan Pariwisata Sumbar pergerakan arus kunjungan wisata ke Sumatera Barat dari tahun ke tahun mengalami kenaikan baik itu wisatawan nusantara maupun wisatawan mancanegara (Febrianto \& Fitriani, 2019). Kota Padang adalah kota terbesar di pantai barat Pulau Sumatera sekaligus ibu kota dari Provinsi Sumatera Barat, Indonesia. Kota ini merupakan pintu gerbang barat Indonesia dari Samudera Hindia. Pantai Purus merupakan salah satu objek wisata andalan Kota Padang.

Pantai Purus merupakan salah satu objek wisata andalan Kota Padang. kebijakan tertuang dalam Peraturan Walikota Padang Nomor 253 Tahun 2014 tentang Penetapan Pantai Padang sebagai kawasan Pariwisata di Kota Padang. Pantai Purus yang berlokasi di barat Kota Padang yang sejajar dengan berbagai objek wisata yang lain seperti Pantai Padang yang hanya berjarak $2 \mathrm{~km}$ dan juga Taman Muaro Binguang yang letaknya bersebelahan dengan Pantai Purus. Pantai Purus memiliki pesisir yang landai, cantik dan area pasirnya juga cukup luas dengan memiliki lebar 30m - 50m dari jalan raya sampai ke arah laut dengan memiliki tekstur yang halus dan lembut sehingga sangat cocok digunakan untuk area bermain pasir bagi anak-anak yang dibawa ke tempat ini. Pasir Pantai Purus ini tidak berwarna putih bersih, akan tetapi berwarna kecoklatan. Ombak yang terdapat disini cukup besar yaitu sekitar 2 meter dan juga bergulung-gulung dengan memantulkan bunyi yang keras. Ombak pantai ini juga sering dijadikan wahana untuk berselancar bagi para peselancar.

Perkembangan pembangunan wisata Pantai Purus yang semakin hari semakin diupayakan pembangunannya serta fasilitas yang disediakan juga sangat cocok bagi para wisatawan baik wisata keluarga maupun untuk muda-mudi. Beberapa fasilitas umum juga tersedia di sekitar Pantai Purus seperti WC umum lengkap dengan tempat untuk mandi membersihkan diri jika ada pengunjung yang mandi air laut, trotoar yang nyaman termasuk 
fasilitas bagi penyandang disabilitas. Hal ini membuat Pantai Purus ini juga semakin hari semakin ramai dikunjungi oleh wisatawan baik dalam negeri maupun luar negeri.

Berdasarkan beberapa hal di atas dalam perkembangannya Pantai Purus berubah menjadi tempat wisata yang juga dimanfaatkan sebagai sumber mata pencaharian. Selain ditemukan pedagang di sepanjang pesisir pantai juga terlihat beberapa pengamen yang mencari nafkah dengan menghibur wisatawan yang datang.

Pengamen yang ada di Kawasan Wisata Pantai Purus Padang dilatarbelakangi oleh beberapa faktor selain memanfaatkan kawasan wisata yang ramai pengunjung yaitu sulitnya mencari pekerjaan serta pendidikan yang rendah membuat mereka memilih mengamen yang bisa dilakukan dengan menyanyi tanpa memerlukan ijazah. Mereka mengamen mulai dari siang sekitar pukul dua siang selepas zuhur hingga malam sekitar pukul 10 malam, pada hari Sabtu dan Minggu bisa sampai pukul 12 malam. Pengamen yang ada di Pantai Puruih ini juga memiliki berbagai strategi dalam menarik perhatian pengunjung meskipun tidak jauh berbeda dengan pengamen pada umumnya. Misalnya pengamen yang ada di Pantai Puruih ini mengubah penampilannya bergaya seperti biduan dengan memakai baju perempuan dan memakai make up padahal dia laki-laki dan yang lainnya seperti biasa memakai gitar serta membawa speaker lengkap dengan mikrofonnya. Meskipun pekerjaannya hanya sebagai pengamen, pengamen yang ada di Pantai Puruih ini mempunyai pemikiran yang maju. Mereka mempunyai pola pikir yang baik serta tekat yang kuat dalam berusaha mengubah taraf hidupnya agar menjadi lebih baik. Oleh karena itu tujuan penelitian ini melihat pengamen dalam melakukan tanggungjawabnya sebagai kepala keluarga. Peneliti mengungkapkan strategi pengamen dalam meningkatkan ekonomi di kawasan wisata Pantai Purus Padang. Penelitian ini dianalisis dengan menggunakan teori tindakan sosial yang dikemukakan oleh Max Weber. Menurut Weber, yang dimaksud tindakan sosial itu adalah tindakan individu sepanjang tindakannya itu mempunyai makna atau arti subyektif bagi dirinya dan diarahkan kepada tindakan orang lain (Douglas)

\section{Metode Penelitian}

Pendekatan yang digunakan dalma penelitian ini adalah pendekatan kualitatif tipe studi kasus. Penelitian kualitatif adalah penelitian yang bermaksud untuk memahami fenomena tentang apa yang dialami oleh subjek penelitian misalnya perilaku, persepsi, motivasi, tindakan dan lainnya (Suwandi, 2008). Tipe peneltian studi kasus diharapkan dapat mengungkapkan strategi yang digunakna pengamen dalam upaya peningkatan ekonomi di Kawasan Wisata Pantai Purus Padang. Teknik pemilihan informan penelitian purposive sampling yaitu teknik penentuan sampel dengan pertimbangan tertentu, artinya sampel adalah orang yang ahli dibidang yang akan diteliti (Sugiyono, 2013). Jumlah informan pada penelitian ini sebanyak 13 orang. Pengumpulan data dilakukan dengan cara wawancara dan observasi dan dianalisis menggunakan teknik analisis data yang dikembangkan oleh Miles dan Hubberman meliputi reduksi data, penyajian data dan penarikan kesimpulan (Emzir, 2010).

\section{Hasil dan Pembahasan}

Pengamen adalah sebutan untuk penyanyi jalanan, sehingga banyak yang menyebutnya sebagai pengamen jalanan. Pengamen merupakan komunitas yang relatif baru dalam kehidupan pinggiran perkotaan, setelah kaum gelandangan dan pemulung (Pribadining, 2011). Pengamen timbul akibat adanya kemiskinan dan kesenjangan pendapatan di kota (Kristina, 2009). Hidup di kota tentu tidak mudah dengan karakteristik masyarakat perkotaan yang bersifat individualistik menyebabkan adanya persaingan satu sama lain dalam 
memperoleh suatu pekerjaan, sedangkan lapangan kerja yang tersedia tentunya harus disesuaikan dengan keahlian dan keterampilan pendidikan yang cukup (Oktaviani, S, Zulkarnain, R, 2018). oleh karena itu muncul pekerjaan sektor informal salah satunya pengamen yang memanfaatkan lokasi wisata di kota karena banyak dikunjungi masyarakat.

Salah satu temuan dari penelitian yang telah dilakukan terkait Strategi Pengamen dalam Meningkatkan Ekonomi di Kawasan Wisata Pantai Puruih Kota Padang ditemukan bahwa strategi pengamen dalam meningkatkan ekonomi yaitu mengoptimalkan pendidikan anakanaknya. Menyadari kehidupannya yang jauh dari kata mampu sebagai seorang pengamen ia tidak ingin anaknya mempunyai masa depan yang sama seperti orang tuanya. Pengamen berharap anaknya mempunyai masa depan yang baik, bisa mendapatkan pekerjaan yang baik dan hidup layak serta berkecukupan.

Pengamen mencari nafkah dengan memanfaatkan lokasi wisata Pantai Purus yang ramai dikunjungi. Dengan menghibur pengunjung melalui nyanyiannya pengamen berharap pengujung dapat memberikan imbalan atas penampilannya. Berbagai cara dilakukan pengamen agar mendapatkan hasil yang maksimal dengan memanfaatkan waktu semaksimal mungkin, menghibur pengunjung dengan kalimat-kalimat yang mengundang tawa dan sampai penampilanpun dipermak se unik mungkin agar menarik perhatian pengungjung.

Penghasilan pengamen setiap harinya saat ini rata-rata Rp 50.000 sampai Rp 100.000 pada hari biasa, sedangkan di akhir minggu seperti Jumat, Sabtu dan Minggu bisa mencapai Rp 150.000 sampai $R p 200.000$ atau sekitar Rp 2.000.000 sampai Rp 3.000.000 perbulan. Penghasilan itu murni diperoleh dari hasil mengamen selama kurang lebih 10 jam setiap harinya atau sekitar $70-80$ jam dalam seminggu. Mereka berangkat kira-kira pukul 13.00 WIB sampai 14.00 WIB sehabis sholat zuhur dan pulang pukul 23.00 WIB atau bisa sampai pukul 24.00 WIB. Pengamen bisa semakin lama pulang jika pengujung dirasa masih ramai mendatangi kawasan wisata Pantai Puruih pada saat malam hari. Pengamen yang ada di Kawasan Wisata Pantai Puruih menyadari pentingnya arti pendidikan bagi anak-anak mereka. Alasan mereka memilih menjadi pengamen adalah agar dapat mengupayakan pendidikan anak semaksimal mungkin. Latarbelakang pendidikan yang hanya sampai ditingkat Sekolah Dasar (SD) membuat mereka berfikir dalam memilih pekerjaan yang tidak memerlukan ijazah namun hasilnya cukup untuk memenuhi kebutuhan keluarga terutama memenuhi kebutuhan sekolah anaknya. Hal ini membuat pengamen giat mengamen agar dapat menyekolahkan anaknya. Pengamen lebih mengutamakan penggunaan uang untuk biaya sekolah anak selain untuk membeli keperluan lain seperti perabotan rumah tangga atau membeli barang-barang lainnya.

Temuan penelitian ini dianalisis menggunakan teori tindakan sosial yang dikemukakan oleh Max Weber. Menurut Weber, yang dimaksud tindakan sosial itu adalah tindakan individu sepanjang tindakannya itu mempunyai makna atau arti subyektif bagi dirinya dan diarahkan kepada tidakan orang lain (Douglas, 2010). Menurut Weber tindakan sosial dibagi menjadi empat tipe, yaitu tindakan rasional, tindakan rasional instrumental, tindakan afektif dan tindakan tradisional. Tindakan sosial instrumental yang dilakukan oleh pengamen yang lebih memilih menggunakan hasil mengamen untuk memenuhi kebutuhan sekolah anaknya daripada membeli hal-hal yang lain merupakan salah satu upaya pengamen agar anaknya bisa menjadi orang yang sukses dan bisa meningkatkan taraf hidup keluarganya dimasa yang akan datang. Penelitian ini menjadi salah satu kajian dimana apapun keadaan orang tua diluar sana pasti menginginkan yang terbaik untuk anaknya. Pengamen membuktikan bahwa untuk mengupayakan pendidikan anak tidak harus memiliki pendidikan yang baik juga serta uang yang banyak. Akan tetapi pengamen memiliki niat dan tujuan yang baik agar dapat mengupayakan pendidikan yang baik bagi anak-anaknya. Pendidikan yang rendah membuat 
pengamen merasa sangat sulit dalam bersain didunia kerja membuat pengamen mengupayakan pendidikan anaknya agar mampu bersaing dalam dunia kerja nantinya.

\section{Kesimpulan}

Kepala rumah tangga yang ada pada penelitian ini memilih mengamen sebagai suatu pekerjaan untuk memenuhi tanggungjawabnya sebagai kepala keluarga yang harus menafkahi anak-anak dan istrinya. Tindakan sosial yang dilakukan kepala rumah tangga ini dipengaruhi oleh beberapa faktor diantaranya cacat fisik yang membuat ia tak bisa melakukan pekerjaan lain selain mengamen, selain itu pendidikan yang rendah membuat ia tak bisa bersaing dengan pencari kerja lainnya yang mempunya skill yang lebih baik. Hal tersebut menjadi salah satu faktor yang membuat pengamen ingin berusaha keras menyekolahkan anaknya agar tidak memeiliki masa depan yang sama dengannya.

\section{Daftar Pustaka}

Antoro, A. (2014). Potensi Pariwisata Pantai Goa Cemara dan Upaya Pengembangannya di Desa Gadingsari Kecamatan Sanden Kabupaten Bantul. Retrieved from http://eprints.uny.ac.id/id/eprint/18319

Douglas, Ritzer, G dan Goodman, J. (2010). Teori Sosiologi Modern. Jakarta: Kencana.

Emzir. (2010). Metodologi Penelitian Kualitatif: Analisis Data. Jakarta: Raja Grafindo Persada.

Febrianto, A., \& Fitriani, E. (2019). Masyarakat Air Manis Sadar Wisata. Abdi: Jurnal Pengabdian dan Pemberdayaan Masyarakat, 1(1), 28-36. https://doi.org/10.24036/ abdi/vol1-iss $1 / 6$

Fitriani, E., Selinaswati, S., \& Mardhiah, D. (2018). Partisipasi Masyarakat Dalam Pembangunan Ekowisata Sungai Pinang. Socius, 4(2), 83-95. doi:10.24036/scs.v4i2. 17

Husni, A., \& Safaat, S. (2019). Pengembangan Desa Wisata Berbasis Partisipasi Masyarakat Lokal Di Desa Teluk Bakau Kecamatan Gunung Kijang Kabupaten Bintan. Socius, 6(1), 1-17. doi:10.24036/scs.v6i1.135

Kristina, D. (2009). Interaksi Sosial Pada Pengamen Disekitar Terminal Tirtonadi Surakarta. Skripsi. Universitas Muhammadiyah Surakarta

Oktaviani, S, Zulkarnain, R. (2018). Tanggapan Masyarakat Tentang Keberadaan Pengamen Anak di Lingkungan Wisata. Jurnal of Community Development, 1(2), 1-8.

Pribadining, H. (2011). Studi Korelasi Antara Persepsi Terhadap Lingkungan Sosial Dengan Motivasi Menjadi Pengamen.http://eprints.ums.ac.id/id/eprints/15931

Prihandoko, A. (2008). Analisis Potensi Obyek Wisata Alam di Kabupaten Semarang. Skripsi. Universitas Muhammadiyah Surakarta

Purwanti, N. (2013). Pengaruh Jumlah Kunjungan Wisatawan terhadap Pendapatan Asli Daerah Kabupaten Mojokerto Tahun 2006-2013. Jurnal Ilmiah Tahun 2014, 1-11.

Rohman, A. (2016). Dampak Ekonomi Terhadap Pendapatan Pedagang Kios di Wisata Religi Makam Sunan Drajat Lamongan. Jurnal Ekonomi Syariáh, 3(2), 1-13,

Sugiyono. (2013). Metode Penelitian Kuantitatif, Kualitatif Dan Kombinasi (Mixed Method).

Suwandi, B. (2008). Memahami Penelitian Kualitatif . Jakarta: Rineka Cipta.

Syafrini D, Susilawati N, dan Hasmira, M. (2016). Partisipasi Masyarakat Lokal dalam Mengembangkan Kawasan Wisata Keluarga. Socius, 3(2), 83-95.

Syafrini, D., \& Fernandes, R. (2018). Dampak Pergeseran Kebijakan Kota Tambang Menjadi Kota Wisata Tambang Berbudaya Pada Kehidupan Sosial Ekonomi Masyarakat Di Kota Sawahlunto. Socius, 4(2), 74-82. doi:10.24036/scs.v4i2.23. 